\title{
Phenotypic features and molecular characterization of plasmids in Salmonella abortusovis
}

\author{
Mauro M. Colombo, ${ }^{1}$ Guido Leori, ${ }^{2}$ Salvatore Rubino, ${ }^{3}$ Antonella Barbato ${ }^{2}$ and \\ Piero CAPPUCCINELli ${ }^{3 *}$ \\ ${ }^{1}$ Dipartimento di Biologia Cellulare e dello Sviluppo, Università di Roma 'La Sapienza', Italy \\ ${ }^{2}$ Istituto Zooprofilattico Sperimentale della Sardegna, Sassari, Italy \\ ${ }^{3}$ Istituto di Microbiologia e Virologia, Università di Sassari and Porto Conte Research Laboratories, Istituto di Genetica \\ Molecolare del CNR, Sassari, Italy
}

(Received 7 August 1991; revised 1 November 1991; accepted 19 November 1991)

\begin{abstract}
The phenotypic and genotypic characteristics of 69 wild-type strains of Salmonella abortusovis from Sardinia and other Italian regions, representing four different epidemic outbreaks, were studied. Biochemical profiles, pathogenicity factors, resistance to antibacterial drugs and genomic organization were investigated. None of the strains tested showed any haemagglutination with different types of red blood cells, and electron microscopy revealed no fimbriae. Adhesivity to epithelial cells was present in all strains tested. Only $16 \%$ of the strains were resistant to streptomycin, and no other drug resistances were found. The restriction patterns of chromosomal DNA did not show heterogeneity and a high-molecular-mass $(50-67 \mathrm{~kb})$ plasmid was found in all strains. Restriction analysis of plasmid DNA from strains from different geographical areas, collected over a period of 30 years, showed a HindIII restriction profile characterized by two patterns, one with three fragments, stable and common to all strains, and a second polymorphic pattern with five fragments. The stable pattern included a $3.7 \mathrm{~kb}$ HindIII fragment that hybridized with a $S$. typhimurium probe containing a virulence region including the $s p v C$ and $s p v D$ genes. These studies allowed us to outline a genetic correlation among $S$. abortusovis isolated from different outbreaks.
\end{abstract}

\section{Introduction}

Salmonella is a genus of enterobacteria which includes several serovars with different host specificity. Besides Salmonella serovars well known as human pathogens, there are other serovars that are specific for animals, including $S$. dublin (cattle), $S$. typhisuis (swine), $S$. pullorum and $S$. gallinarum (poultry) (Groisman et al., 1990). All can occasionally cause disease in humans (Groisman et al., 1990).

Salmonella abortusovis is a highly specific pathogen for sheep; it causes abortion, and is sometimes responsible for the death of ewes. In endemic areas abortion can occur in $30-50 \%$ of the sheep in a flock, mainly during the first pregnancy. After the infection, a natural immunity is generally acquired (Jack, 1968; Pardon et al., 1988). S. abortusovis less frequently causes mortality

*Correspondence to Dr P. Cappuccinelli, Istituto di Microbiologia e Virologia, Viale S. Pietro 43B, 07100 Sassari, Italy. Tel. 79 228302; fax 79212345 . in lambs; infection in humans has never been clearly demonstrated. The bacteria can be easily isolated from sheep vaginal discharges up to four weeks after abortion, from foetal membranes and from organs of the foetus such as liver, spleen, brain and stomach. $S$. abortusovis infection can seriously damage a sheep-based economy, such as that of Sardinia, where most of the strains described in this report were collected. Disease control in endemic areas is based on vaccination; however, most of the vaccines currently used give only partial protection and their value is limited to particular geographical areas (Pardon et al., 1990).

Development of effective vaccines requires an understanding of the molecular basis of $S$. abortusovis pathogenicity, but very few reports have been published on the biology and pathogenicity of this organism (for reviews see Jack, 1968; Pardon et al., 1988). Popoff et al. (1984) described high-molecular-mass plasmids in $S$. abortusovis homologous to $S$. typhimurium plasmids, suggesting that they may contribute to pathogenicity. Many authors have described a molecular epidemiology 
of pathogenic bacteria based on plasmid content and polymorphisms (e.g. Brunner et al., 1983; Farrar, 1983; Sorum et al., 1988).

The aim of this paper is to give a general description of 69 strains collected in diverse geographical areas of Italy (Sardinia, Abruzzo) during 30 years of epidemic episodes. We analysed biochemical profiles, antibiotic resistance, haemagglutination activity, the presence of fimbriae and adhesivity to epithelial cells in vitro. Restriction analysis of chromosomal and plasmid DNA has allowed us to describe genetic correlations among $S$. abortusovis isolates from different outbreaks.

\section{Methods}

Bacterial strains. The $S$. abortusovis strains used in this study were from diverse geographical locations and were obtained either from culture collections or from epidemic episodes.

All 61 Sardinian strains were isolated in the period 1978-1990 and named SS 1 to SS 61. Seven strains (TE 1 to TE 7) were isolated during 1978-1990 by the Istituto Zooprofilattico Sperimentale dell'Abruzzo e del Molise, Teramo, and were kindly provided by Dr D. Galassi; one strain isolated in 1951 (BS 1170) was provided by M. Zavanella, Istituto Zooprofilattico Sperimentale della Lombardia e dell'Emilia. In addition to the 69 Italian strains, two strains from France were studied: the first, 27K IP, was a gift from Dr M. Popoff (Unité 199, Institut Pasteur, Paris), the second, INRA Rv6, which is used as a live vaccine, was purchased from Rhône-Mérieux, Lyon; it corresponds to the ATCC strain 31685 .

The 61 strains we isolated were obtained from foetal tissues such as stomach, brain, liver and spleen, and from vaginal discharges; samples were inoculated onto Trypticase soy agar (Oxoid) supplemented with $5 \%(\mathrm{v} / \mathrm{v})$ sheep blood. Preliminary selection was performed in Triple sugar iron medium (Oxoid) and further biochemical identification was performed using the API 20E System (BioMérieux) and Salmonella polyvalent antisera (Sclavo Diagnostics). Serovar identification was performed by standard agglutination using specific antisera provided by Sclavo and employed as directed by the manufacturer. The results were in accordance with the antigenic profile described in Bergey's Manual (Brenner, 1984) for $S$. abortusovis $(0: 4,12: c: 1,6)$.

Bacterial strains were maintaned at $-70^{\circ} \mathrm{C}$ in Luria broth containing $25 \%(\mathrm{v} / \mathrm{v})$ glycerol.

Media and antibiotics. Reagents for Luria broth (LB), nutrient broth (NB) and Isosensitest Agar were purchased from Difco.

Drug resistances were tested by assessing the breakpoint in Isosensitest agar containing ampicillin $\left(50 \mu \mathrm{g} \mathrm{ml}^{-1}\right)$, chloramphenicol $\left(25 \mu \mathrm{g} \mathrm{ml}^{-1}\right)$, streptomycin $\left(20 \mu \mathrm{g} \mathrm{ml}^{-1}\right)$, spectinomycin $\left(75 \mu \mathrm{g} \mathrm{ml}^{-1}\right)$, kanamycin $\left(30 \mu \mathrm{g} \mathrm{ml}^{-1}\right)$, oxytetracycline $\left(10 \mu \mathrm{g} \mathrm{ml}^{-1}\right)$, rifampicin $\left(100 \mu \mathrm{g} \mathrm{ml}^{-1}\right)$, nalidixic acid $\left(40 \mu \mathrm{g} \mathrm{ml}^{-1}\right)$ or cloxacillin $\left(5 \mu \mathrm{g} \mathrm{ml}^{-1}\right)$ as described by Miller (1972). All the antibiotics were purchased from Sigma.

Biochemical analysis. All strains were analysed for biochemical characteristics using the API-20 E system (BioMérieux). To study sugar fermentations we used Bacto phenol red broth base and the following Difco sugar disks: adonitol, maltose, D-mannose, trehalose, D-xylose, raffinose, dextrose, lactose and dulcitol.

Haemagglutination assays and electron microscopy. For haemagglutination, human, chicken, rabbit, guinea-pig and sheep red cells were used and bacterial cultures were grown in NB by the method of serial static broth cultures according to Duguid et al. (1975) or overnight in LB as described by Leunk \& Moon (1982). The test was performed in microtitre plates, and Salmonella typhimurium, S. typhi, S. choleraesuis and Escherichia coli strains were used as positive controls.

To detect the presence of fimbriae by transmission electron microscopy we used: (1) bacteria grown overnight on LB medium; (2) bacteria cultivated as described by Duguid et al. (1975); (3) bacteria directly isolated from the stomach of aborted foetuses. Cells were washed in saline buffer, dropped on a grid covered with collodion and negatively stained using uranyl acetate. The grids were examined with a Jeol, JSM electron microscope.

Cell culture and adherence assay. Lamb kidney epithelial cells were grown in Eagle minimum essential medium (MEM; Gibco) and placed on coverslips ( $16 \mathrm{~mm}$ diameter) in order to obtain a total of $4 \times 10^{4}$ cells per coverslip. The bacterial strains to be tested were grown in LB to exponential phase. The bacteria were washed with PBS, resuspended in MEM medium and added to the kidney cells ( $1: 70$ cells/bacteria), allowed to adhere for $1-2 \mathrm{~h}$ and then fixed and processed for Giemsa staining as described by Hale \& Boventre (1979).

Curing of plasmid DNA. The following curing agents were employed: acridine orange (Sigma) from 200 to $500 \mu \mathrm{g} \mathrm{ml}^{-1}$, ethidium bromide (Sigma) at $30 \mu \mathrm{g} \mathrm{ml}^{-1}$, temperature $45^{\circ} \mathrm{C}$. The test strain (SS 44) was grown for more than 30 subcultures under curing conditions in LB. The cultures were then streaked on LB agar and incubated at $37^{\circ} \mathrm{C}$ for $24 \mathrm{~h}$. Thirty colonies were picked randomly and their plasmid content examined in DNA mini-preparations as described below:

Extraction and purification of DNA. To prepare chromosomal DNA, bacteria were grown in $100 \mathrm{ml} \mathrm{LB}$ to saturation. DNA from $S$. abortusovis strains was isolated according to Ausubel et al. (1987) Plasmid DNA suitable for restriction analysis was extracted and purified by the method of Kado \& Liu (1981).

DNA restriction analysis. DNA was digested with restriction enzymes purchased from Boehringer Mannheim or Promega, using the reaction buffers provided by the suppliers. Agarose for electrophoresis was from Bio-Rad; Tris/acetate/EDTA was used as running buffer for $0.8 \%$ agarose gels $10 \mathrm{~cm}$ long. $\lambda$ DNA digested with HindIII (Boehringer Mannheim) was used as size marker. All procedures were performed according to Sambrook et al. (1989).

Plasmid hybridization with pYA426 probe. Plasmid pYA426 (Gulig \& Curtiss, 1988) contains a region of the $S$. typhimurium virulence plasmid carrying three genes: the virulence genes $s p v C$ and $s p v D$, and the orf $E$ gene, which is not required for virulence (Gulig \& Chiodo, 1990; P. Gulig, A. L. Caldwell \& V. A. Chiodo, unpublished results). [We have used the new $s p v$ nomenclature for Salmonella virulence plasmids according to P. Gulig, H. Danbara, D. E. Guiney, A. J. Lax, F. Norel \& M. Rhen (unpublished).] This probe was kindly provided by Roy Curtiss III and Paul Gulig, Washington University, St Louis, MO, USA. Plasmids from $S$, abortusovis were digested with HindIII and tested by Southern blotting hybridization using the virulence probe. The probe was radioactively labelled with a random priming labelling kit, as described in the protocol of the manufacturer (Boehringer Mannheim). Colonies of the $61 \mathrm{~S}$. abortusovis strains under study were hybridized with the probe using colony hybridization transfer $\mathbf{M}$ membranes (Du Pont de Nemours) according to the manufacturer's instructions.

\section{Results}

\section{Phenotypic analysis}

The biochemical profile of the $S$. abortusovis strains we isolated in Sardinia is consistent with the profile reported 
Table 1. Adhesivity of seven Sardinian strains and two strains from Abruzzo to lamb kidney epithelial cells

\begin{tabular}{ll}
\hline \hline Strain & $\begin{array}{c}\text { No. of bacteria } \\
\text { per cell }\end{array}$ \\
\hline SS 2 & $18.0 \pm 4.47$ \\
SS 40 & $36.0 \pm 6.48$ \\
SS 20 & $38.0 \pm 7.44$ \\
SS 44 & $41.0 \pm 6.61$ \\
SS 35 & $50.0 \pm 8.57$ \\
SS 21 & $62.5 \pm 8.56$ \\
SS 19 & $64.0 \pm 5.61$ \\
TE 1 & $62.6 \pm 5.1$ \\
TE 4 & $50.0 \pm 5.6$ \\
\hline \hline
\end{tabular}

* Mean $\pm S D$; at least 50 kidney cells were scored for each strain.

by Sanchis \& Abadie (1980). We should point out that the use of API 20E does not distinguish between $S$. abortusovis and $S$. typhi, as reported also by Plagemann (1989), since both are ornithine decarboxylase (ODC) negative; therefore further serological identification must be done.

All strains were sensitive to all antibiotics tested, except that 11 strains $(16 \%)$ were resistant to streptomycin. This resistance did not appear to be correlated with the presence of plasmid DNA.

Compared to the positive control, none of the strains under study showed haemagglutination with human, chicken, rabbit, guinea-pig or sheep red blood cells.

Electron microscopy of all strains, either grown in culture or isolated directly from the stomach of aborted foetuses, showed a typical Salmonella morphology, with flagella present. We were unable to detect filamentous appendages such as fimbriae (data not shown).

Table 1 shows the adhesivity of seven randomly chosen Sardinian strains, and two strains from Abruzzo (TE 1 and TE 4), to kidney epithelial cells in vitro. We considered a strain positive for adhesivity if, following Giemsa staining, at least 10 bacteria were attached to each cell. All strains tested showed high adhesivity $(>10$ bacteria per cell).

\section{Chromosomal and plasmid DNA analysis}

Chromosomal DNA extracted from 20 randomly chosen isolates was utilized for strain characterization. These isolates were representative of four epidemics, one from Nuoro and one from Sassari, Sardinia, and two from Abruzzo, and included three reference strains (INRA Rv6, BS 1170 and 27K IP). Agarose gel electrophoresis of DNA digested with $H$ indIII, EcoRV, EcoRI, BglI and BamHI showed, as expected, a conserved banding pattern in all strains examined (data not shown).
The presence of plasmids in $S$. abortusovis was also examined in all 69 strains. A single large plasmid, ranging in size from 50 to $67 \mathrm{~kb}$ (see Table 2 for seven representative strains) was found in all $S$. abortusovis strains examined. These plasmids were highly stable, being resistant to all methods employed for curing.

Restriction analysis was performed on 41 strains (including the three reference strains) to determine the precise molecular size and profile of the plasmids. The most reproducible results were achieved with HindIII and EcoRI. Results with BamHI and PstI were not satisfactory for the purpose of these studies. The 38 epidemic strains yielded four different plasmid profiles with HindIII; the populations thus identified corresponded to the areas from which the strains originated. The first population (18 plasmids examined), was isolated in the Sassari area and is represented by SS 35; the second population (13 plasmids examined), represented by SS 44, came from Nuoro; TE 1 and TE 4 (representative of groups of four and three strains, respectively) were derived from two different outbreaks in Abruzzo. The three reference strains gave plasmid profiles that were distinct from each other and from the above four groups. Fig. 1 shows the plasmid profiles of the three reference strains and a representative strain from each of the four epidemics mentioned above. Table 2 is a schematic representation of Fig. 1. It shows the sizes of the fragments obtained by HindIII digestion, with the estimated total size of the plasmids.

Following HindIII digestion, all the plasmids except that from SS 35 showed eight fragments. The total number of different fragments obtained from the seven plasmids was 20 . There were three fragments common to all plasmids, with sizes of $3.7,5.2$ and $12 \mathrm{~kb}$. An additional $2.6 \mathrm{~kb}$ fragment was common to all plasmids except that from TE 4 . The plasmid profiles of SS 44 and BS 1170 (from different Italian regions) were identical except for the largest fragment. Plasmids obtained from strains TE 1 and TE 4, which are from the same geographical area, had five common fragments out of eight. The two French plasmids had six fragments in common out of eight; the $12 \mathrm{~kb}$ common fragment of the vaccine strain appeared to be a doublet. Analogous results were obtained after plasmid digestion with EcoRI, showing three common fragments (8.6, 8.0 and $0.9 \mathrm{~kb}$ ) in all the profiles examined (data not shown); however, HindIII digestion was the most effective in defining the common and the polymorphic patterns in the restriction profiles and therefore it was preferred for the genetic analysis.

The plasmids digested with HindIII shown in Fig. 1, representing the seven different profiles of $S$. abortusovis, were hybridized with a DNA probe containing the virulence genes $s p v C$ and $s p v D$ of the $S$. typhimurium 


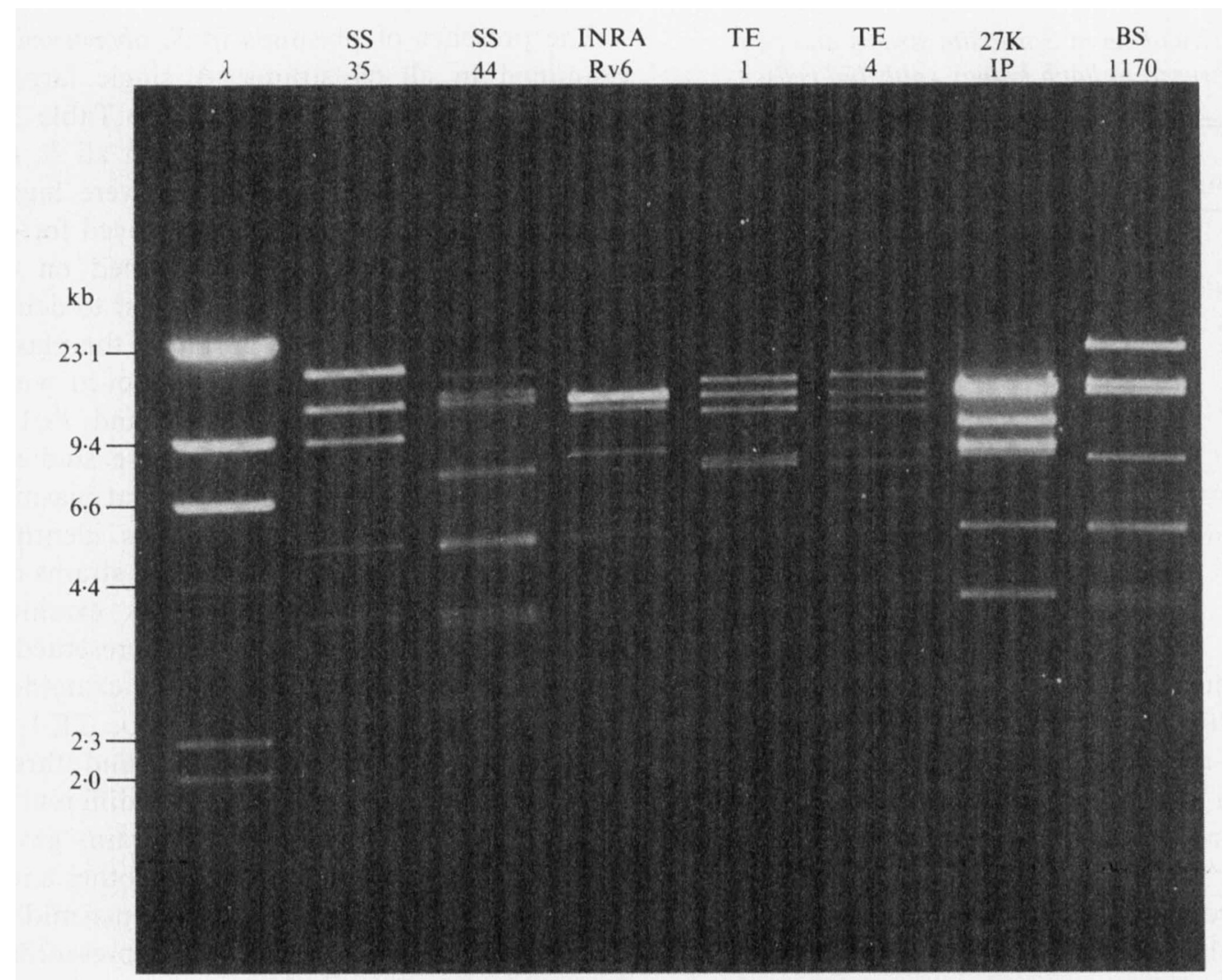

Fig. 1. HindIII digests of plasmid DNAs from representative $S$. abortusovis strains. The leftmost lane contains $\lambda$ DNA with HindIII as size marker. The results are represented schematically in Table 2.

Table 2. Schematic representation of the HindIII restriction patterns of plasmid DNAs of S. abortusovis shown in Fig. I

\begin{tabular}{|c|c|c|c|c|c|c|c|}
\hline $\begin{array}{l}\text { Fragment } \\
\text { size (kb) }\end{array}$ & $\begin{array}{l}\text { SS } \\
35\end{array}$ & $\begin{array}{l}\text { SS } \\
44\end{array}$ & $\begin{array}{c}\text { INRA } \\
\text { Rv6 }\end{array}$ & $\begin{array}{c}\text { TE } \\
1\end{array}$ & $\begin{array}{c}\mathrm{TE} \\
4\end{array}$ & $\begin{array}{c}27 \mathrm{~K} \\
\text { IP }\end{array}$ & $\begin{array}{c}\text { BS } \\
1170\end{array}$ \\
\hline $20 \cdot 0$ & & & & & & & + \\
\hline $17 \cdot 3$ & + & & & & & & \\
\hline $15 \cdot 7$ & & + & & & & & \\
\hline 14.0 & & & & & + & & \\
\hline 13.7 & & & & + & & & \\
\hline 13.0 & & + & & & & & + \\
\hline 12.5 & & & & & & + & \\
\hline 12.0 & + & + & $t^{d}$ & + & + & + & + \\
\hline 11.0 & & & + & & & & \\
\hline $10 \cdot 5$ & & & & + & + & & \\
\hline $9 \cdot 4$ & + & & & & & + & \\
\hline $8 \cdot 2$ & & & + & & + & + & \\
\hline 7.8 & & & & + & & & \\
\hline $7 \cdot 6$ & & + & & + & + & & + \\
\hline $6 \cdot 1$ & & & & & + & & \\
\hline $5 \cdot 2$ & + & + & + & + & + & + & + \\
\hline 3.7 & + & + & + & + & + & + & + \\
\hline 3.6 & & + & & & & & + \\
\hline $2 \cdot 6$ & + & + & + & + & & + & + \\
\hline $2 \cdot 1$ & & & + & & & + & \\
\hline Plasmid & & & & & & & \\
\hline size $(k b)$ & $50 \cdot 2$ & $63 \cdot 4$ & 56.8 & $63 \cdot 1$ & $67 \cdot 3$ & $55 \cdot 7$ & 67.7 \\
\hline
\end{tabular}

d, Doublet. virulence plasmid. All seven plasmids contained a $3.7 \mathrm{~kb}$ fragment that hybridized with the probe (Fig. 2). This result indicates that in all strains the $3.7 \mathrm{~kb}$ HindIII fragment represents the same fragment and not coincidental fragments, and that this fragment is part of the common virulence region. We have demonstrated by colony hybridization with the pYA426 probe the presence in all 61 Sardinian strains of a plasmid having homology with the virulence region of $S$. typhimurium (data not shown).

\section{Discussion}

In this paper we have characterized 69 wild-type Italian strains of $S$. abortusovis by phenotypic and genotypic features.

Some authors have described a high percentage of streptomycin resistance in $S$. abortusovis from different geographical areas (Pardon et al., 1990); however we found only a few strains $(16 \%)$ resistant to streptomycin. This may be explained by the fact that Sardinian sheep are seldom treated with drugs.

Regarding the expression of pathogenicity factors, all 


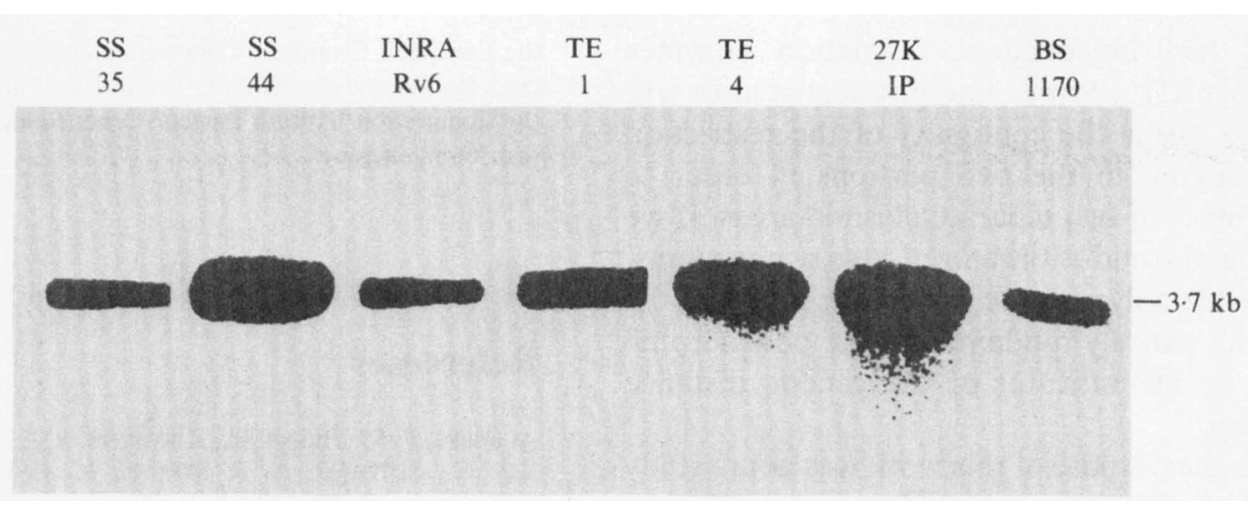

Fig. 2. Autoradiography of a Southern blot of the gel in Fig. 1, and probed with pYA426, containing virulence genes from the $S$. typhimuriu:n virulence plasmid.

$S$. abortusovis strains tested were able to adhere to epithelial cells even though they lacked fimbriae and haemagglutination activity. This may suggest that, as in other enterobacteria, the epithelial cell receptors are not related to other phenotypic characters such as fimbriae commonly associated with cell adhesivity (Groisman et al., 1990). Epithelial cell adhesivity could represent an important mechanism of pathogenicity in S. abortusovis, allowing both colonization of the intestinal tract after ingestion and localization in the chorionic epithelium of the placenta after haematic dissemination. However, it is possible that specific metabolites required for $S$. abortusovis infection are present in the placental tissue. Alternatively, bacteria may be present inside macrophages, as described for other Salmonellae (Field et al., 1986), and carried through the placenta after becoming established in the lymph nodes.

Since, as expected, restriction enzyme analysis of chromosomal DNA did not show any polymorphism among the strains tested, and the other phenotypic features were not reliable as genetic markers, we focused our attention on plasmid DNA.

A single plasmid of high molecular mass $(50-67 \mathrm{~kb})$ was found in all $S$. abortusovis strains examined. This is in accordance with the results of Popoff et al. (1984), who described in this organism plasmids with about $60 \%$ homology with $S$. typhimurium plasmids. Williamson $e t$ al. (1988) found common virulence regions on plasmids from 11 serovars of Salmonella, including $S$. abortusovis. Poppe et al. (1991) demonstrated that plasmid pYA420, constructed from a $S a l \mathrm{I} / \mathrm{Bg} / \mathrm{I}$ fragment of the $60 \mathrm{MDa}$ virulence-associated plasmid of $S$. typhimurium containing the $s p v C$ and $s p v D$ virulence genes, hybridized with plasmid DNA of $S$. choleraesuis, $S$. dublin, $S$. enteritidis, $S$. gallinarum and $S$. pullorum.

This report confirmed the existence of a wellconserved region among the large plasmids of Salmonella serovars, demonstrating the existence of a $3.7 \mathrm{~kb}$ region having homology with the probe pYA424, which contains the rightmost $3.2 \mathrm{~kb}$ of the $8.2 \mathrm{~kb}$ common virulence region (Gulig \& Chiodo, 1990). Transposon Tn 5 insertion mutagenesis of the virulence region of $S$. typhimurium has been carried out in the $\operatorname{spv} C$ gene, which encodes a $28 \mathrm{kDa}$ protein. These experiments have demonstrated that this protein is a major virulence factor for S. typhimurium pathogenesis (Gulig, 1990; P. Gulig, A. L. Caldwell \& V. A. Chiodo, unpublished results). It is possible that spvC could have an important role in $S$. abortusovis virulence. However, the possibility that the plasmids we detected may contribute to pathogenicity is still under investigation. The DNA region of $S$. typhimurium containing $s p v C$ and $s p v D$ could constitute a specific probe for virulence-associated plasmids in $S$. abortusovis, as reported for other Salmonella serovars (Poppe et al., 1991).

In order to correlate phenotypic traits with the presence of plasmids, curing was attempted by several methods, without success. This is not surprising since difficulies in curing Salmonella plasmids are well documented (Poppe \& Gyles, 1988; Tinge \& Curtiss, 1990).

From our data concerning the sample of 41 restriction profiles, even though we cannot assume that these restriction patterns in the plasmids are conserved in all the strains, we can observe the following: $(a)$ the existence of a common restriction pattern, suggesting a possible stable portion of DNA as large as $20 \mathrm{~kb}$, containing a common virulence region; $(b)$ the homology of a $3.7 \mathrm{~kb}$ HindIII fragment with the virulence genes $s p v D$ and $s p v C$ belonging to the Salmonella virulence plasmid; $(c)$ the maintenance of this stable portion of DNA for 30 years of epidemic episodes in different geographical areas; $(d)$ the presence of a portion of about $40 \mathrm{~kb}$ characterized by a polymorphism in the restriction pattern. These observations are based on the restriction analysis, and the existence of a common pattern is 
confirmed by two independent restriction enzymes (HindIII and EcoRI). Further fine physical studies will be necessary to assess the contiguity of the restriction fragments belonging to the two portions in order to define the existence of two separate plasmid areas. If we assume that the plasmid is organized into two portions, one stable and one polymorphic, we can deduce that the variability is not entirely random, and the polymorphic portion could be an indicator of the genetic distance between isolates.

Even though the purpose of this work was not to study the epidemiology of $S$. abortusovis, but to describe the main phenotypic and genotypic features of Sardinian strains, we suggest that for further field investigations the plasmid restriction profile and its polymorphism may be a useful method for describing the epidemiology or at least the genetic relatedness of $S$. abortusovis wild-types, since no other phenotypic markers feasible for this purpose have yet been identified. In support of this idea, the strains isolated in the same epidemic location show identity in the part that we define as the polymorphic portion. On the other hand, strains collected in different epidemics, or of different clonal origin, show different degrees of polymorphism in the variable portion. In fact both strains SS 35 and SS 44, representing two different Sardinian populations, and the two French strains, one virulent and the other naturally attenuated, show polymorphic portions with high polymorphism, indicating a certain genetic distance between them. A lower level of polymorphism was found in strains TE 1 and TE 4, which are representative of two different outbreaks from Abruzzo, suggesting a higher genetic relatedness. The plasmid of strain BS 1170 shows a polymorphic portion similar to that of SS 44, although the Mediterranean sea and 31 years separate the epidemic episodes from which these strains derive. This suggests that no major genomic rearrangements have occurred in the plasmid, and we can hypothesize that strains with a close clonal relationship affected the flocks in the two distant epidemics.

We should mention that $S$. abortusovis, after being spread in the pasture by the dissemination of aborted foetuses, foetal membranes and vaginal discharges, can survive for several months in a quiescent state, creating a stability in the clonal origin of further infections. It is difficult to track the spread of $S$. abortusovis infection in flocks, due to the mobility of the sheep inside the same geographical area and also in different, more distant areas.

We are grateful to Gennaro D'Urso, Paola Melis and particularly to Paul Gulig for criticism in reading the manuscript. We thank Roberto Bruni and Marina Pisano for technical assistance.

This work was supported by grants from Consiglio Nazionale delle Ricerche (CNR) 89.05352MZ77, CNR 90.01373.4, MPI (60\%), by the European Economic Community contract no. TS2-0153-I, 'Medicine, Health and Nutrition in Tropical and Subtropical Areas', and by the Foundation 'Istituto Pasteur-Cenci Bolognetti', who supplied the restriction enzymes.

\section{References}

Ausubel, F. M., Brent, R., Kingston, R. E., Moore, D. D., Seidmar, J. G., Smith, J. A. \& StruHL, K. (1987). Current Protocols in Molecular Biology. New York: Greene Publishing Associates \& Wiley-Interscience.

BRENNER, D. J. (1984). Family I. Enterobacteriaceae. In Bergey's Manual of Systematic Bacteriology, vol. 1, pp. 408-516. Edited by N. R. Krieg \& J. G. Holt. Baltimore: Williams \& Wilkins.

Brunner, F., Margadant, A., Peduzzi, R. \& Piffaretti, J. (1983). The plasmid pattern as an epidemiological tool for Salmonella typhimurium epidemics: comparison with the lysotype. Journal of Infectious Diseases 148, 7-11.

Duguid, J. P., Anderson, E. S., Alfredsson, G. A., Barker, R. \& OLD, C. D. (1975). A new biotyping scheme for Salmonella typhimurium and its phylogenetic significance. Journal of Medical Microbiology 8, 149-166.

FARRAR, W. E. (1983). Molecular analysis of plasmids in epidemiologic investigations. Journal of Infectious Diseases 148, 1-6.

Field, P. I., Swanson, R. V., Haidaris, C. G. \& Hefrron, F. (1986). Mutants of Salmonella typhimurium that cannot survive within the macrophage are virulent. Proceedings of the National Academy of Sciences of the United States of America 83, 5189-5193.

Groisman, E. A., Fields, P. I. \& Hefrron, F. (1990). Molecular biology of Salmonella pathogenesis. In Molecular Basis of Bacterial Pathogenesis, pp. 251-272. Edited by B. H. Iglewski \& V. L. Clark. New York: Academic Press.

Gulig, P. (1990). Virulence plasmids of Salmonella typhimurium and other salmonellae. Microbial Pathogenesis 8, 3-11.

Gulig, P. A. \& CHIODO, V. A. (1990). Genetic and DNA sequence analysis of the Salmonella typhimurium virulence plasmid gene encoding the 28,000-molecular weight protein. Infection and Immunity 58, 2651-2658.

Gulig, P. A. \& CURtiss, R., III (1988). Cloning and transposon insertion mutagenesis of virulence genes of the 100-kilobase plasmid of Salmonella typhimurium. Infection and Immunity 56, 3262-3271.

Hale, T. L. \& Boventre, P. F. (1979). Shigella infection of Henle intestinal epithelial cells: role of the bacterium. Infection and Immunity 24, 879-886.

JACK, E. J. (1986). Salmonella abortus ovis: an atypical Salmonella. Veterinary Record 82, 558-561.

KADO, C. I. \& LIU, S. T. (1981). Rapid procedure for detection and isolation of large and small plasmids. Journal of Bacteriology 145, 1365-1373.

LEUNK, R. D. \& Moon, R. J. (1982). Association of type 1 pili with the ability of livers to clear Salmonella typhimurium. Infection and Immunity 36, 1168-1174.

MiLleR, J. H. (1972). Experiments in Molecular Genetics. Cold Spring Harbor, NY: Cold Spring Harbor Laboratory.

Pardon, P., Sanchis, R., Marly, J., Lantier, F., Pepin, M. \& POPOFF, M. (1988). Salmonellose ovine due à Salmonella abortusovis. Annales de Recherches Vétérinaires 19, 221-235.

Pardon, P., Marly, J., Lantier, F. \& Sanchis, R. (1990). Vaccinal properties of Salmonella abortusovis mutants for streptomycin: screening with an ovine model. Annales de Recherches Vétérinaires 21 , $57-67$.

Plagemann, O. (1989). The differential diagnosis of Salmonella abortus ovis and Yersinia pseudotuberculosis in sheep abortions. Zentralblatt für Veterinärmedizin 36, 509-514.

POPPE, C. \& GYLES, C. L. (1988). Tagging and elimination of plasmids in Salmonella of avian origin. Veterinary Microbiology 18, 73-87. 
Poppe, C., Curtiss, R., III, Gulig, P. A. \& Gyles, C. L. (1991) Hybridization studies with a DNA probe derived from the virulence region of the $60 \mathrm{Mdal}$ plasmid of Salmonella typhimurium. Canadian Journal of Veterinary Research 53, 378-384.

Popoff, M. Y., Miras, L., Coynalt, C., Lasselin, C. \& Pardon, P. (1984). Molecular relationships between virulence plasmids of Salmonella serotypes typhimurium and dublin and large plasmids of other Salmonella serotypes. Annales de Microbiologie 135, 389-398.

SAmbrooK, J., Fritsch, E. F. \& Maniatis, T. (1989). Molecular Cloning: a Laboratory Manual. Cold Spring Harbor, NY: Cold Spring Harbor Laboratory.

SANCHIS, R. \& ABADIE, G. (1980). Salmonella abortus ovis. Étude de 112 souches. Comparative Immunology, Microbiology and Infectious Diseases 3, 517-523.

Sorum, H., Poppe, T. T. \& Olsvik, D. (1988). Plasmid in Vibrio salmonicida isolated from salmonids with hemorrhagic syndrome (Hitra disease). Journal of Clinical Microbiology 26, 1679-1683.

Tinge, S. A. \& CURTiss, R., III (1990). Conservation of Salmonella typhimurium virulence plasmid maintenance regions among Salmonella serovars as a basis for plasmid curing. Infection and Immunity 58, 3084-3092.

Williamson, C. M., Baird, G. D. \& Manning, E. J. (1988). A common virulence region on plasmids from eleven serotypes of Salmonella. Journal of General Microbiology 134, 975-982. 